\title{
Integration of biocontrol agents with fungicide, weedicide and plant growth regulator for management of stem and root rot of jute
}

\author{
S.K. Bhattacharyya ${ }^{1}$, K. Sen ${ }^{2}$, R.K. De ${ }^{1}$, A. Bandopadhyay ${ }^{3}$, C. Sengupta $^{2}$ and N.K. \\ Adhikary $^{4 *}$ \\ ${ }^{1}$ Crop Protection Division, Central Research Institute for Jute and Allied Fibres (ICAR), Barrackpore, Kolkata- \\ 700120, INDIA \\ ${ }^{2}$ Microbiology Laboratory, Department of Botany, University of Kalyani-741235, Nadia, INDIA \\ ${ }^{3}$ Applied Mycology \& Molecular Plant Pathology Laboratory, Department of Botany, University of Calcutta, 35, \\ Ballyguange Circular Road, Kolkata-700 019, INDIA \\ ${ }^{4}$ Department of Plant Pathology, Directorate of Research, BCKV, Kalyani-741235, Nadia, INDIA \\ *Corresponding author. E-mail: nayan.bckv@gmail.com \\ Received: June 24, 2016; Revised received: February 9, 2017; Accepted: April 28, 2017
}

\begin{abstract}
Combination of chemical fungicides (viz., Carbendazim 50 WP and Tebuconazole 250 EC) and biocontrol agents (viz., Pseudomonas fluorescens Psfl1, P. striata Pst1, Azotobacter chrococcum Azbc3, Bradyrhizobium japonicum Brj4, Trichoderma aureoviridae S12, T. harzianum JTV2, T. virens JPG1, Aspergillus niger AN15 strains respectively either singly or in consortium) were used to counteract Macrophomina phaseolina, the causal organism of stem and root rot of jute. In addition, suitable plant growth regulator viz., Indole-3-acetic acid $(100-1.0 \mu \mathrm{g} / \mathrm{ppm})$ and herbicide Quizalofop ethyl $5 \%$ EC were used to augment the activity of Trichoderma. T. aureoviridae strain S12 was found to be the best among the eight isolates screened for tolerance against the two fungicides and herbicide at a concentration of $10000-500 \mu \mathrm{g}$ respectively as well as against $M$. phaseolina (Inhibition=72.33\%) in-vitro. This strain showed best compatibility with other strains and highest tolerance to fungicide i.e., Carbendazim $50 \%$ (up to $500 \mu \mathrm{g})$. Highest number $\left(13.7 \times 10^{6}\right)$ of active spores was recorded at a concentration of $25 \mathrm{ppm}$ of IAA under invitro condition. S12 recorded a biocontrol efficiency of $61.8 \%$ against stem rot of jute along with significant plant growth promotion and fibre production. Plant biomass also increased up to $7.5-12.1 \%$ and fibre production $37.0-$ $39.9 \%$ with fungal and bacterial consortium + carbendazim seed dressing and soil drenching. These biocontrol fungi and PGPR consortium with high tolerance to fungicide, weedicide and plant growth regulator up to certain extent may be potentially exploited in IDM which may be a low cost technology in jute and allied fibre crops.
\end{abstract}

Keywords: Biocontrol, Fungicide, Growth regulator, Macrophomina phaseolina, Trichoderma, Weedicide

\section{INTRODUCTION}

In recent times, to satisfy the demand of everincreasing global population, chemical fertilizers and pesticides are indispensable in modern agriculture for achieving higher yield of crops Nonetheless, indiscriminate uses of chemicals impart hazardous effect on soil-microbe-ecological balance, cause phytotoxicity and lysis of beneficial organisms (Dłużniewska, 2003), leads to alarming resurgence of pesticide resistant mutants of pathogens, consequently results in grave environmental pollution due to residual problem (Sayyed and Patel, 2011). This has diverted the attention of plant pathologists toward alternate methods for the control of plant diseases.

Biological control of phytopathogens is an alternative and attractive preposition as it mimics the natural way of balancing population of living organisms without disturbing the microbial diversity of soil while maintaining exponential population growth of the biocon- trol agents as well. Over and above it helps to increase the yield by suppressing pathogen inoculum, protects plants against infection by inducing resistance and all the more enables to attain a safe and clean environment (Bandopadhyay and Bandopadhyay, 2004).

To this end, Plant Growth-Promoting Rhizobacteria (PGPR), Biofertilizers and Biocontrol fungi in consortial assortment has presented immense potential in field evaluation as effective substitute for agrochemicals. Coincidentally, some soil-borne root infecting fungi cannot be eradicated by chemical fungicides because they produce persistent resting structures like sclerotia, pycnidia etc. for their survival for a longer period of time under adverse environmental conditions (Baker and Cook, 1974). Under such circumstances, direct antibiosis and hyper-parasitism exhibited by most biocontrol fungi needs to be exploited simultaneously, integrating with plant growth regulator and herbicide improves yield by triggering active spore germination of biocontrol fungi and increases fungi- 
cide tolerance respectively (Adekunle et al., 2001). Thus, inclusion of all such components to integrated disease management (IDM) is ultimate practical approach for cost effective sustainable agriculture (Bandopadhyay et al., 2006).

Trichoderma species are known to suppress infection of root by soil-borne pathogens like $M$. phaseolina, Rhizoctonia solani, Fusarium sp. and Pythium sp. on various crops (Ehtesham et al., 1990; Bandopadhyay et al., 2009). Trichoderma also has growth promoting ability that may be in harmony with biological control (Benitez et al., 2004; Dubey et al., 2007).

The combined use of bio-control agents and chemical pesticides has attracted much attention in order to obtain synergistic effects in the control of soil borne diseases (Locke et al., 1985). Reduced amount of fungicide can stress and weaken the pathogen and render its propagules more susceptible to subsequent attack by the antagonist (Hjeljord and Tronsmo, 1998). Srinivas and Ramakrishnan (2002) have reported that integration of bio-control agents with commonly used fungicides showed positive association by reducing the seed infection compared to fungicide and the fungal antagonists individually.

In India and Bangladesh, every year the fiber yield of jute is being reduced by $30 \%$ due to stem and root rot disease caused by Macrophomina phaseolina (Tassi) Goid, which has continued to be a burning problem over a century (Gupta and Chauhan, 2005). This study was aimed at evaluating the efficacy of the proposed PGPR consortium comprising of Pseudomonas fluorescens Psfl1, P. striata Pst1 (Phosphobacter), Azotobacter chrococcum Azbc3, Bradyrhizobium japonicum Brj4 and fungal consortium consisting of T. harzianum JTV2, T. virens JPG1, Aspergillus niger AN15 and Trichoderma aureoviridae S12, in conjunction with low concentration of chemical fungicides viz.,

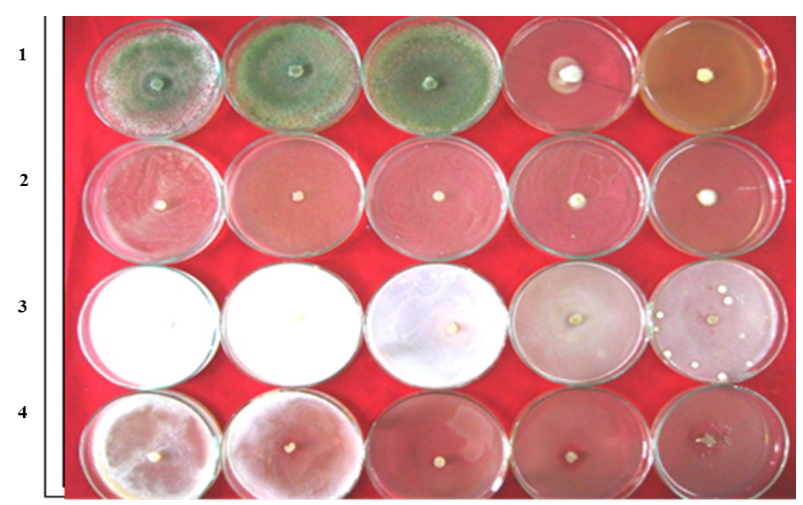

Fig.1. Differential tolerance of Trichoderma aureoviridae (AB916337) as JTV-1 to fungicide, weedicide and Plant growth regulator chemicals in-vitro.

Concentrations Left to right: 1. Indole-3 Acetic Acid 100, 50, 25, 10, $1 \mu \mathrm{g}(0.01-0.0001 \%)$ a.i. 2. Carbendazim $10000,5000,2500,1000,500 \mu \mathrm{g}(1.0,0.5,0.25,0.1,0.05 \%)$ a.i. 3. Tebuconazole 10000 - $500 \mu g(1.0-0.05 \%)$ a.i. 4. Quizalofop ethyl 10000 - $500 \mu \mathrm{g}(1.0-0.05 \%)$ a.i.
Carbendazim 50 Wettable Powder and Tebuconazole 250 Emulsifiable Concentration in an integrated management of stem rot of jute.

\section{MATERIALS AND METHODS}

Microbial cultures: Four wild-type PGPR strains Psfl1 (Pseudomonas fluorescens), Pst1 (P. striata), Azbc3 (Azotobacter chrococcum), Brj4 (Bradyrhizobium japonicum) and four PGPF strains JTV2 (Trichoderma harzianum), JPG1 (Gliocladium virens $=T$. virens), AN15 (Aspergillus niger) and S12 (T. aureoviridae) were used in the experiment. These strains were isolated from jute rhizosphere growing in the alluvial tracts of the Ganges, identified by $16 \mathrm{~S}$ and $18 \mathrm{~S}$ rDNA sequencing and analyzing the sequence using program (http://www.ddbj.nig.ac.jp). These strains were applied as seed bacterization, culture suspension of spores adjusted to $2 \times 10^{5}$ spores per $\mathrm{cm}^{3}$.

Macrophomina phaseolina (Tassi) Goid isolated from infected jute stem. Inoculum prepared as $5 \mathrm{~mm}$ disc on $60 \mathrm{~g}$ sterile discarded jute seeds $+2 \%$ dextrose mix. Inoculum added at a concentration $1.5 \mathrm{~g} / \mathrm{kg}$ of soil.

Jute cultivar: Corchorus olitorius L. var. JRO 524 (Navin) susceptible to stem and root rot of jute was used in this experiment. Seeds were planted in $30 \mathrm{~cm}$ diameter pots filled with non-sterile soil and grown under green- house conditions at $35-37^{\circ} \mathrm{C}$, Relative Humidity $=80-90 \%$.

In-vitro evaluation: T. aureoviridae was evaluated for tolerance against fungicides, herbicide and growth regulator before pot trial using food poison method in-

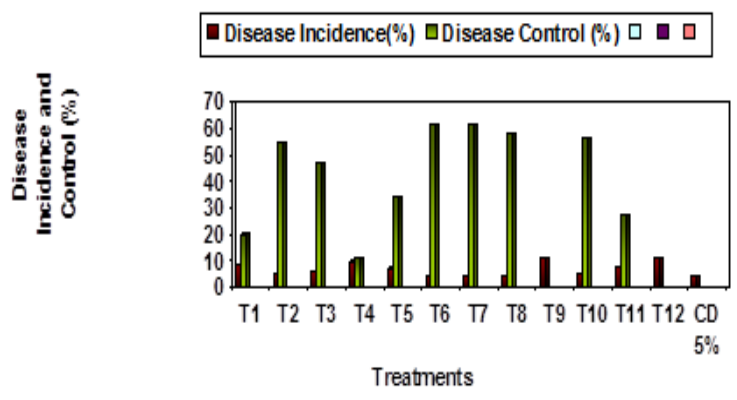

Fig. 2. Effect of bioformulations on disease incidence and control of Macrophomina.

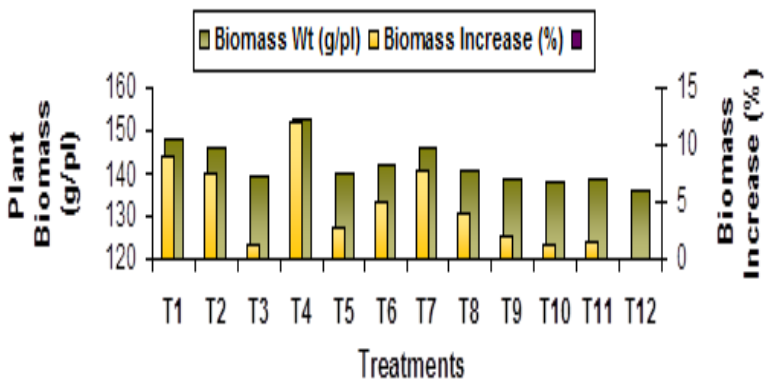

Fig. 3. Effect of bioformulations on biomass of Macrophomina. 


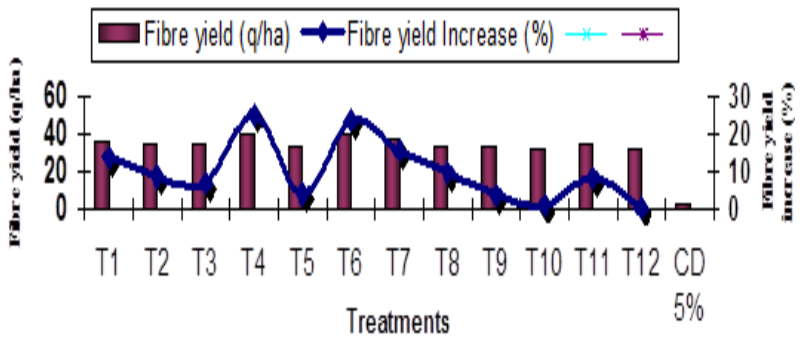

Fig. 4. Effect of bioformulations on fibre yield of Macrophomina.

vitro. Growth regulator indole-3 acetic acid or IAA (25 ppm), fungicides viz., Carbendazim $50 \mathrm{WP}$ and Tebuconazole 250 EC and weedicide Quizalofop ethyl $5 \%$ EC were added to Potato Dextrose Agar medium (PDA: Potato Peeled-200 g, Dextrose-20 g, Agar-20 g, water-1 L) to get final concentration of 500, 1000, 2500,5000 and $10,000 \mu \mathrm{g}$ for fungicides and weedicide respectively and $1,10,25,50,100 \mu \mathrm{g}$ for growth regulator chemicals. Number of spores at different concentration of IAA was checked by Haemocytometer. PDA without any chemicals served as control. All the above experiments were carried out in 3 replications. A $5 \mathrm{~mm}$ inoculum disc of Trichoderma aureoviridae was cut from the margin of actively growing colony and placed in centre of each Petri plate. Petri plates were incubated at $25 \pm 2{ }^{\circ} \mathrm{C}$. Radial growth of Trichoderma aureoviridae was observed daily. After 72 hours of incubation the germination process was stopped by adding a drop of formalin. Next a degree of spore's germination was estimated. Percent inhibition of radial growth of the stem rot pathogen offered by all the Trichoderma isolates was also checked and confirmed by dual culture before formulation used (Bhattacharyya et al., 2014). Biocontrol agents were also screened for fungal cell wall-degrading enzyme (chitinase, $\beta-1,3$ glucanase), siderophore and $\mathrm{HCN}$ production before pot experimentation.

In-vivo evaluation: The evaluation was done after invitro selection of efficient Trichoderma sp. tolerant to agrochemicals and plant growth regulator (Khan and Shahzad, 2007) following the compatible combinations among them (Bandopadhyay and Bandopadhyay, 2004). The bio-formulations with the selected isolates were evaluated in the following manner.

Pot evaluation trial: Effectiveness of commercial Talc (Hi-media) + Fly ash based bio formulations of fungal consortium and Kaolin (Hi-media) based bacterial consortium singly and integrated with fungicides like Carbendazim 50\% (Bavistin) and weedicide Quizalofop ethyl $5 \%$ EC (Targa super) were evaluated for disease control, plant biomass and fibre production in jute.

Bio-formulations used: Three bio pesticide formulations developed with different microbial inoculantcombination, viz. 1. Fungal consortium of Trichoderma aureoviridae + Gliocladium virens $(=T$. virens $)$ as

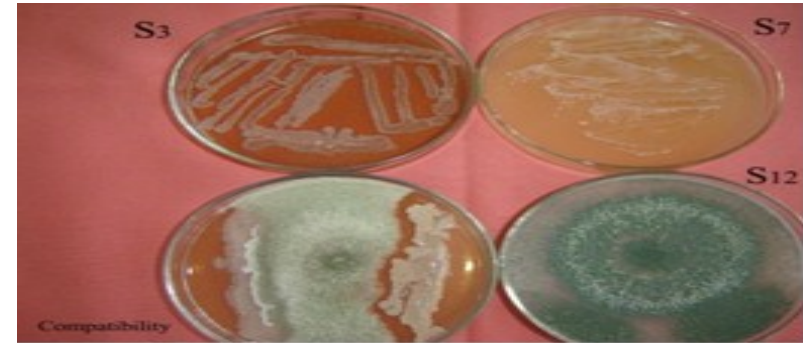

Fig. 5. Test of Compatibility/Synergistic effect of Trichoderma aureoviridae.

S12 and JTV2 + Aspergillus niger (AN15). 2. Bacterial consortium of Pseudomonas + Phosphobacter + Azotobacter Azbc 3. Fungal + Bacterial consortium of (T. aureoviridae + A. niger $=\mathrm{PGPF})+($ Pseudomonas fluorescens Psfl1+ Phosphobacter Pst1 + Azotobacter Azbc3= PGPR)

Seed dressing@10 g kg-1 seed, Soil inoculants@1 $\mathrm{kg}$ in $300 \mathrm{sq} \mathrm{m} .=0.3$ hectare area, Fungicide Seed Treatment by Carbendazim $50 \%$ @ g/2 ml kg-1 seed, Weedicide Spray by Quizalofop ethyl (Targa Super) @ $2.5 \mathrm{ml} \mathrm{l}^{-1}$ water, Plant growth regulator $12 \mathrm{hrs}$ seed soaked in Indole-3-acetic acid (IAA)@ 25 ppm, Treatment: 12, Replication: 3, Pot Size: $30 \mathrm{~cm}$ in diameter, Design: RBD, Fertilizer application: $\mathrm{N}_{40} \mathrm{P}_{20} \mathrm{~K}_{0}$.

\section{Treatments}

T1 - Fungal Consortium SD

T2 - Bacterial Consortium SD

T3 - Trichoderma + Carbendazim SD

T4- Fungal and Bacterial Consortium $(1: 1)+$ Tebuconazole SD

T5- Fungal and Bacterial Consortium (1:1) + Carbendazim SD

T6- Fungal Consortium + Carbendazim SD + Fungal Consortium Soil Drench 15 DAS

T7 - Bacterial Consortium+ Carbendazim SD + Bacterial Consortium Soil Drench 15 DAS

T8 - Trichoderma formulate SD + Targa Super Spray 21 DAS

T9- Fungal Consortium Seed Dressing + Targa Super Spray 21 DAS

T10- Bacterial Consortium Seed Dressing + Targa Super Spray 21 DAS

T11- Fungal Consortium + Bacterial Consortium Seed Dressing + Targa Super Spray 21 DAS

T12 - Control/Check

$\mathrm{SD}=$ Seed dressing, DAS $=$ Day's after Sowing.

\section{RESULTS AND DISCUSSION}

Tolerance to agrochemicals, inhibition of pathogen by dual culture plate, in-vitro biocontrol potential and identification of the antagonists: In-vitro studies revealed that Trichoderma aureoviridae remains active up to a concentration of $500 \mu \mathrm{g} / \mathrm{ppm}(0.05 \%$ a.i. $)$ of fungicide, Carbendazem $50 \%$ even after 72 hours, although the growth of the isolate was relatively slow, time specific and the active spores are expressed in 
minute to moderate in number and their proliferation was quite late over the control (Fig. 1). It was observed that all the fungicides and herbicides used weakened antagonistic fungi spores germination. Out of all the fungicidal preparations, the most powerful fungi static effect was observed for Tebuconazole 250 $\mathrm{EC}$, which in the concentration of $500 \mu \mathrm{g}$ completely inhibited spores germination in all the fungi tested. Also Quizalofop ethyl $5 \%$ EC (Targa Super) herbicides in the dose of $500 \mu \mathrm{g}$ significantly inhibited the development of germ tubes in the saprophytes researched. However, growth gradually decreases with increase in concentration and completely inhibited at $1000-10000 \mu \mathrm{g} / \mathrm{ppm}(0.1-1.0 \%$ a.i.). In contrast to this, Fungicide Tebuconazole 250 EC and weedicide Quizalofop ethyl $5 \%$ EC is very toxic and completely suppresses the growth of $T$. aureoviridae even at the lowest concentration. Thus, the level of tolerance of $T$. aureoviridae to the agrochemicals may be rated as Carbendazim > Tebuconazole and Quizalofop ethyl. As time progresses the effect of the chemicals decrease but mycelia and conidia of the selected fungi slowly proliferate up to certain extent. On the other hand, the activity of the spores and their expression in number are increased up to certain extent as the concentration of plant growth regulator (IAA) increases. The activities of this isolate are promising and very effective in disease management and plant biomass production under field condition, the results of the experiments into the effect of selected abiotic factors varied on effectiveness of Trichoderma genus fungi when jute seed-dressing was applied singly and in integration (Fig. 2-4) as presented below. The factors applied in the experiment modified the antagonistic effect of Trichoderma genus fungi applied in a form of seed dressing. The effect of the factors studied was considerably related to the saprophyte pathogen relationship and the direction of changes depended on the fungus species as well as the factor kind. The inhibition offered by Trichoderma isolates and bacterial biocontrol-agents against the pathogen ranged between 68.88-72.33 \%. T. aureoviridae tested positive for siderophore and $\mathrm{HCN}$ production along with fungal cell wall degrading enzymes, chitinase and $\beta-1,3$ glucanase production. The nucleotide sequence of $18 \mathrm{~S}$ rDNA of $T$. aureoviridae deposited at DDBJ, Japan was assigned the accession number: AB916337.

Disease management: Seed dressing with bio formulations of fungal consortium + Carbendazim, bacterial consortium + carbendazim with bacterial consortium and fungal consortium soil drench 15 DAS (T6 and T7) resulted in controls of pathogen Macrophomina phaseolina up to $61.8 \%$. Whereas, seed dressing alone with Trichoderma formulate + Targa super spray 21 DAS (T8) resulted in control of Macrophomina stem and root diseases in jute up to $58.1 \%$ and bacterial consortium + Targa super spray 21 DAS (T10) or bacterial consortium seed dressing only (T2) can control
56.3-54.5\% disease over control. Trichoderma and Carbendazim seed dressing + Targa super spray 21 DAS (T3) and fungal + bacterial consortium + carbendazim seed dressing (T5) achieved 47.2-34.5\% disease control (Fig. 2).

Plant growth and fibre yield: Plant biomass and fibre production could be best achieved with fungal + bacterial consortium along with Tebuconazole seed dressing (T4) of which biomass increased up to $12.1 \%$ and fibre production $39.9 \%$. Plant biomass increased up to $9.1 \%$ being followed by fungal consortium seed dressing (T1) In contrast, highest fibre production could be achieved with fungal consortium + carbendazim seed dressing + fungal consortium soil drench 15 DAS (T6). Intermediate results were obtained for bio formulations comprising of bacterial consortium + carbendazim seed dressing + bacterial consortium soil drench 15 DAS (T7) both in case of plant biomass and fibre yield increase. Seed dressed with fungal and bacterial consortium + Tebuconazole (T4) and fungal consortium + carbendazim seed dressing + fungal consortium soil drench 15 DAS (T6) showed highest fibre yield of 39.8 and $39.6 \mathrm{q} \mathrm{h}^{-1}$ respectively. For Trichoderma seed dressing + Targa Super spray (T8) and fungal + bacterial consortium seed dressing along with Targa super spray (T11) almost 34-35 $\mathrm{q} \mathrm{ha}^{-1}$ fibre yield of jute was recorded (Fig. 3 and 4).

Stem rot of jute caused by Macrophomina phaseolina has been a century old disease affecting the crop globally, especially in US and south-east Asia including Bangladesh and India, whereby decreasing fibre yield by $30 \%$ (Gupta and Chauhan, 2005). Till date no such Macrophomina-rot resistant variety of jute has been launched to counteract the pathogen. The little effort that has been invested on biocontrol is restricted to the use of Trichoderma viride, Aspergillus niger, Pseudomonas fluorescens and Azotobacter sp. respectively (Meena et al., 2014; Roy et al., 2015).

For the first time, this study has exploited both bacterial and fungal consortium in integration with fungicides, Carbendazim $50 \%$ and Tebuconazole $25.9 \%$ w/ w. Moreover this work has documented the use of a novel fungus, Trichoderma aureoviridae that has exhibited tolerance to fungicide and other chemicals as well as growth regulator, IAA. The experiments presented showed that higher concentrations of the used chemicals inhibited mycelium growth, weakened sporulation and spore germination of Trichoderma isolates. Trichoderma sp., an endophytic symbiont has long been investigated as a biological control organism against several soil borne pathogens (Benítez et al., 1998; Lorito et al., 2010). The mechanism of biocontrol has been largely attributed to the production of allelo-chemicals that include antifungal diffusible and volatile metabolites with antibiotic activity, cell wall degrading enzymes, $\mathrm{Fe}^{3+}$ iron chelating molecules, siderophores, besides its positive influence on growth promotion and increased tolerance to various abiotic 
stresses is remarkable (Gravel et al., 2007). Biocontrol results either due to competition for nutrients and space or as a result of the ability of Trichoderma to produce and/or resist metabolites that either impedes spore germination (fungi -stasis), kill the cells (antibiosis) or modify the rhizosphere. Biocontrol may also result from a direct interaction between the pathogen itself and the BCA due to mycoparasitism, which involves physical contact and synthesis of hydrolytic enzymes, toxic compounds and/or antibiotics that act synergistically with the enzymes (Howell, 2002; Djonovic et al., 2006).

Simultaneously, Trichoderma has been shown to be capable of increasing plant growth and yield. This increases indirectly accounts for the reduction in plant diseases. This fungus could also have the potential to stimulate plant growth independent of any plant disease. Applications of Trichoderma in plant production, therefore, can reduce the use of fungicides, growth regulators and labour which eventually will lower the production costs and environmental impact (Pandya and Saraf, 2010).

The resistance to fungicides, herbicide exhibited by our strain, T. aureoviridae can be justified by evidence from previous work (Chet et al., 1997), can be accounted for the presence of ABC system of transportation (Harman et al., 2004). However, unlike the previous works, this strain has exhibited a very high tolerance to Carbendazim, i.e., up to $500 \mu \mathrm{g} / \mathrm{ppm}$, whereas usual range being (1-50 ppm) (Roy et al., 2015). As observed by Ahemad and Khan (2010), likewise this strain also showed an increase in plant growth promoting activity (evidenced from increase in fibre production and biomass increase) with the increase in herbicide dose until the toxic level was reached.

High tolerance of $T$. aureoviridae to growth regulator, IAA, being $25 \mathrm{ppm}$, can be correlated to the increase in chitinase activity as has been observed by Badri et al., 2007. He opined that most Trichoderma strains can tolerate IAA upto $30 \mathrm{ppm}$. The role of Trichoderma aureoviridae is immense in controlling some important soil and seed borne diseases of crop plants. The most important advantage of this is: very much compatible with others, have no adverse effects on others and play synergistic associations with others (Fig. 5).

With the development of fungal pathogen resistance to fungicides, adverse effects of fungicides on natural enemies and public awareness of environmental conservation there has been a renewed interest in the development of crop varieties with resistance to pathogens/pests. Mostly, fungicides produce undesirable effects on non-targeting organisms, so the use of microorganisms that antagonize plant pathogenic fungi is risk free (Benitez et al., 2004). Moreover, the combination of fungicide tolerant biological control agents with reduced levels of fungicide integrated control strategies would promote the degree of disease suppression similar to that achieved with full dosage of fungicides (Monte, 2001). There are reports where the biocontrol agents, which can tolerate fungicides up to a certain level, were mixed with fungicides and resulted in eradication of diseases (De Cal et al., 1994). Integrated disease management incorporating cultural and biological control methods with reduced chemical inputs seems to be a promising approach (Latore et al., 1997). The result of the present screening would help in the selection of biocontrol agents, which can be used, with reduced dose of selected fungicides for the control of soil borne plant pathogenic fungi.

The novelty of this study lies in exploiting a novel strain of Trichoderma viz., T. aureoviridae S12 in a fungal consortium along with bacterial consortium. Plant roots support the growth and activities of an array of microorganisms that may impart profound effects on growth and health of plants.

\section{Conclusion}

Numerous species of soil fungi and bacteria flourish in the rhizosphere of plants and activate or stimulate plant growth by a plethora of mechanisms. The difficulty of controlling the pathogen lies in the long surviving ability of sclerotia, its broad host range and lack of resistant jute (Corchorus olitorius L.). Trichoderma spp. is endophytic plant opportunistic symbionts, widely used as biocontrol agents by producing antifungal diffusible and volatile metabolites with antibiotic activity for plant diseases, relatively easy to isolate and ranks top in order of importance besides its positive influence on growth promotion and increased tolerance to various abiotic stresses. Integration of promising plant growth regulator, a bio-fertilizer and bio-control agent is useful for exploitation to achieve higher yield. Inclusion of all such components in the integrated disease management (IDM) is ultimate practical approach for cost effective sustainable agriculture. In the present study, suitable plant growth regulator and chemical fungicide were incorporated to accomplish an acceptable strategy for appropriate IDM system.

\section{ACKNOWLEDGEMENTS}

The authors are grateful to the Director of Central Research Institute for Jute and Allied Fibres, Barrackpore for his active scientific support and also to Director, Directorate of Research; Bidhan Chandra Krishi Viswavidyalaya, Directorate of Research, Kalyani to execute the present investigation along with the financial help provided by DST purse programme of University of Kalyani during the tenure of which this work was carried out is gratefully acknowledged.

\section{REFERENCES}

Adekunle, A. T., Cardwell, K. F., Florini, D. A. and Ikotun, T. (2001). Seed treatment with Trichoderma species for control of Damping-off of Cowpea caused by Macrophomina phaseolina. Biocontr. Sci. Technol., 11: 449 
$-457$

Ahemad, M. and Khan, M. S. (2010). Influence of selective herbicides on Plant Growth Promoting traits of Phosphate solubilising Enterobacter asburiae Strain PS2. Res. J. Microbiol., 5 (9): 849-857

Badri, M., Zamani, M. R. and Motallebi, M. (2007). Effect of Plant Growth Regulators on in vitro biological control of Fusarium oxysporum by Trichoderma harzianum (T8). Pak. J. Biol. Sci., 10 (17): 2850-2855

Baker, K. F. and Cook, R. J. (1974). Biological Control of Plant Pathogens, Freeman, San Francisco, Pp. 433

Bandopadhyay, A. and Bandopadhyay, A. K. (2004). Beneficial traits of Plant Growth Promoting Rhizobacteria and fungal antagonist consortium for biological disease management in bast fibre crop. Indian Phytopathol. 57 (3): 356-357

Bandopadhyay, A. K., Bandopadhyay, A. and Majumder, A. (2006). Antagonistic effect of Trichoderma, Gliocladium, Aspergilius, Penicillium and PGPR isolates on highly virulent isolates (R 9) of M. phaseolina. J. Mycopathol. Res., 44: 323-330

Bandopadhyay, A. Bhattacharya, S. K., Bandopadhyay, A. K. and Reddy, M. S. (2009). Abstract on "Beneficial traits of PGPR mediated disease management and growth promotion in jute and Sunnhemp with bioformulation of activated and wild bio control agents" at First Asian PGPR Congress for Sustainable Agriculture, jointly organized by ANGARU, Rajendranagar, A.P (India) \& Auburn University, U.S.A ; P4.44, Pp. 97

Benítez, T. Delgado-Jarana, J., Rincón, A. M., Rey M. and Limon, M. C. (1998). Biofungicides: Trichoderma as a biocontrol agent against phytopathogenic fungi. In: Pandalai SG (ed.) Recent research developments in microbiology, vol. 2. Research Signpost, Trivandrum, Pp. $129-150$

Benitez, T., Rincon, A. M., Limon, M. C. and Codon, A. C. (2004). Biocontrol mechanisms of Trichoderma strains. Int. Microbiol., 7 (4): 249-260

Bhattacharyya, S. K., Sengupta, C. and Tarafdar, J. (2014). In vitro screening of bio agents from rhizosphere soil against Macrophomina phaseolina and seedling health of jute. J. Mycopathol. Res., 52 (2): 267-272

Chet, I., Inbar, J. and Hadar, I. (1997). Fungal antagonists and mycoparasites. In:Wicklow DT Söderström B (eds.) The Mycota IV: Environmental and microbial relationships. Springer-Verlag, Berlin, Pp. 165-184

De Cal, A., Pascua, S.S. and Melgarejo, P. (1994). In vitro studies on the effects of fungicides on beneficial fungi of peach twig mycoflora. Mycopathologia,126(1):15-20

Djonovic, S., Pozo, M. J., Dangott, L. J., Howell, C. R. and Kenerley, C. M. (2006). Sm1, a proteinaceous elicitor secreted by the biocontrol fungus Trichoderma virens induces plant defense responses and systemic resistance. Mol. Plant Microbe Interact., 19 (8): 838-853

Dłużniewska. J. (2003). Reaction of fungi of Trichoderma genus to selected abiotic factors. Elec. J. Polish Agr. Uni., 6 (2): 4-8

Dubey, S. C., Suresh, M. and Singh, B. S. (2007). Evaluation of Trichoderma species against Fusarium oxysporum f.sp. ciceris for integrated management of chickpea wilts. Biol. Control., 40: 118-127
Ehteshamul-Haque, S., Zaki, M. J. and Ghaffa, R. (1990). A. Biological control of root rot diseases of okra, sunflower, soybean and mung bean. Pak. J. Bot., 22: 121-124

Gravel, V., Antoun, H. and Tweddell, R. (2007). Growth stimulation and fruit yield improvement of greenhouse tomato plants by inoculation with Pseudomonas putida or Trichoderma atroviride: possible role of indole acetic acid (IAA). Soil Biol. Biochem., 39: 1968-1977

Gupta, G. K. and Chauhan, G. S. (2005). Symptoms, Identification and Management of Soybean Diseases. Technical Bulletin, 10. National Research Centre for Soybean, Indore, India, Pp. 92

Harman, G. E., Howell, C. R., Viterbo, A., Chet, I. and Lorito, M. (2004). Trichoderma species-opportunistic, avirulent plant symbionts. Nat. Rev. Microbiol., 2: 43-56

Hjeljord, L. and Tronsmo, A. (1998). Trichoderma and Gliocladium in biological control: an overview. In: Harman G. E., Kubicek, C. P., editors. Trichoderma and Gliocladium. London: Taylor and Francis, pp. 131-152

Howell, C. R. (2002). Cotton seedling pre-emergence damping-off incited by Rhizopus oryzae and Pythium spp. and its biological control with Trichoderma spp. Phytopathol., 92(2): 177-180

Latore, B. A., Agosin, E., San Martin, R. and Vasquez, G. S. (1997). Effectiveness of conidia of Trichoderma harzianum produced by liquid fermentation against Botrytis bunch rot of table grape in Chile. Crop Prot., 16 (3): 209-214

Locke, J.C., Marois, J.J. and Papavizas, G.C. (1985). Biological control of Fusarium wilt of greenhouse-grown chrysanthemums. Plant Dis., 69: 167-169

Lorito, M., Woo, S. L., Harman, G. E. and Monte, E. (2010). Translational research on Trichoderma: from omics to the field. Annu. Rev. Phytopathol., 48: 395-417

Khan, M. O. and Shahzad, S. (2007). Screening of Trichoderma species for tolerance to fungicides. Pak. J. Bot., 39 (3): 945-951

Meena, P. N., Roy, A., Gotyal, B. S., Mitra, S. and Satpathy, S. (2014). Eco-friendly management of major diseases in jute (Corchorus olitorius L.). J. Appl. \& Nat. Sci., 6 (2): 541-544

Monte, E. (2001). Understanding Trichoderma: Between biotechnology and microbial ecology. Int. Microbiol., 4: $1-4$

Pandya, U. and Saraf, M. (2010). Application of fungi as a biocontrol agent and their biofertilizer potential in agriculture. J. Adv. Devel. Res., 1 (1): 90-99

Sayyed, R. Z. and Patel, P. R. (2011) Biocontrol potential of siderophore producing heavy metal resistant Alcaligenes sp. and Pseudomonas aeruginosa RZS3 vis-a-vis organophosphorus fungicide. Indian J. Microbiol., 51 (3): 266 $-272$

Roy, A., Roy, S. K., Chakraborty, G. and Sarkar, S. K. (2015). Effect of Biocontrol Agent Consortia for Ecofriendly Management of Stem and Root Rot in Olitorius Jute caused by Macrophomina phaseolina. Int. J. Biores. Sci., 2 (2): 95-100

Srinivas, P. and Ramakrishnan, G. (2002). Use of native microorganisms and commonly recommended fungicides in integrated management of rice seed borne pathogens. Annu. Plant Prot. Sci., 14 (2): 260-264 